\title{
Dyspnea: The role of psychological processes
}

\author{
Steven De Peuter ${ }^{\mathrm{a}}$, Ilse Van Diest ${ }^{\mathrm{a}}$, Valentine Lemaigre ${ }^{\mathrm{b}}$, Geert Verleden $^{\mathrm{b}}$, \\ Maurits Demedts ${ }^{\mathrm{b}}$, Omer Van den Bergh ${ }^{\mathrm{a}, *}$ \\ ${ }^{a}$ Department of Psychology, University of Leuven, Leuven, Belgium \\ ${ }^{\mathrm{b}}$ Pneumology Department, UZ Gasthuisberg, University of Leuven, Leuven, Belgium
}

Received 18 December 2003; received in revised form 5 April 2004; accepted 26 May 2004

\begin{abstract}
Breathlessness or dyspnea - the subjective experience of breathing discomfort-is a symptom in many pulmonary, cardiovascular, and neuromuscular diseases. It occurs in normals as well during intense emotional states and heavy labor or exercise. In clinical cases, it generally causes severe suffering.

Dyspnea has multifactorial causes and the explanation for the symptom may differ largely among patients. Explanatory models imply the involvement of mechanisms at several levels of functioning, such as afferent signals from the respiratory muscles or blood gas levels related to hypercapnia and hypoxia. Depending on the relative involvement of specific mechanisms and their interactions, dyspnea may be experienced differently and subtypes can be distinguished. More recently, perceptual-cognitive and emotional processes related to symptom perception and interpretation have been investigated in the context of dyspnea.

In this review, we focus on the psychological processes that play part in the perception of dyspnea and formulate some practical guidelines for those who are confronted with dyspnea.
\end{abstract}

(C) 2004 Elsevier Ltd. All rights reserved.

Keywords: Dyspnea; Symptom perception; Respiration; Symptoms; Breathlessness

\section{Introduction}

Dyspnea-breathlessness, or the subjective experience of breathing difficulty or discomfort-is a symptom experienced by many patients with pulmonary, cardiovascular, and neuromuscular diseases, patients on mechanical ventilation (Wong, Lopez-Nahas, \& Molassiotis, 2001), as well as by $70 \%$ of

\footnotetext{
* Corresponding author. Research Group for Stress, Health and Well-Being, Tiensestraat 102, B-3000 Leuven, Belgium.

E-mail address: omer.vandenbergh@psy.kuleuven.ac.be (O. Van den Bergh).
} 
terminally ill cancer patients (Coyne, Viswanathan, \& Smith, 2002). After back pain and fatigue, dyspnea is the third most common presenting symptom in internal medicine (Mahler et al., 1996). It occurs in healthy individuals as well, e.g., during intense emotional states and heavy labor or exercise. As a symptom, it can be hard to treat (Skevington, Pilaar, Routh, \& MacLeod, 1997) and often causes poor quality of life and severe disability. In many cases, it is the only reason why a person seeks medical care and sometimes it is also the only complaint patients consult for.

Moreover, there is a close relation between dyspnea and some domains of psychological (mal)functioning: Anxiety is a common symptom among patients with respiratory disease. Anxiety disorders appear to be the most prevalent psychiatric disorders in clinical samples of patients with pulmonary disease (Smoller, Simon, Pollack, Kradin, \& Stern, 1999). Sensations of shortness of breath, feelings of choking, and chest pain or discomfort are part of the definition of a panic attack in the Diagnostic and Statistical Manual of Mental Disorders (DSM-IV; American Psychiatric Association, 1994). Dyspnea is part of the symptomatology in agoraphobia and hyperventilation syndrome (Rietveld, Everaerd, \& Creer, 2000), and it is a common complaint in Multiple Chemical Sensitivity (MCS; Black, Okiishi, \& Schlosser, 2001). The differential diagnosis of dyspnea and anxiety includes both pulmonary and psychiatric conditions (Smoller et al., 1999).

As a result, diagnosing the cause of the dyspnea is a difficult task, complicated by the variety of (patho)physiological and psychological processes that play a role in the origin of the sensation of dyspnea. The current article focuses on psychological aspects in the perception and reporting of dyspnea. In the first section, we try to define the term dyspnea. The second section gives a brief overview of the most prevalent physiological explanations of dyspnea. Because our focus is on the perception of dyspnea and psychological factors playing a role in that process, these are reviewed more thoroughly in sections three and four, respectively. We conclude with some practical guidelines for caregivers confronted with dyspnea.

\section{A definition of dyspnea}

Dyspnea is a medical term used for a variety of breathing-related phenomena that should not be considered interchangeable. In general, the term refers to "a subjective experience of breathing discomfort that consists of qualitatively distinct breathing sensations that vary in intensity" (American Thoracic Society, 1999, p. 322). "Shortness of breath," "breathlessness," "lack of breath," and "difficulty breathing" are all dyspneic feelings, the one being more general than the other.

As a consequence, no consensus exists on how dyspnea should be measured (Mahler \& Harver, 2000). In some studies, patients have to describe or rate "dyspnea," in other studies "uncomfortable breathing" is questioned, and yet in other studies patients have to choose from a list of different sensations the descriptors that best fit their sensations, or they have to give a global judgement for the set of terms (Banzett, Dempsey, O'Donnell, \& Wamboldt, 2000). Other research uses a very narrow definition and asks patients to rate their degree of dyspnea while disregarding other signs of uncomfortable breathing (Noseda, Schmerber, Prigogine, De Maertelaer, \& Yernault, 1995). In some cases, distinctions between the subjective sensations of the patient and the physical observations of the physician are taken for granted, in other cases they are overlooked (American Thoracic Society, 1999).

Evidence indicates, however, that dyspnea is not a unitary concept: Patients report different sensations depending on the questions asked and depending on the condition causing dyspnea. Elliott et al. (1991) 
investigated dyspnea in 208 patients with cardiac and lung disease and had them choose those descriptions out of a list of 45 that fitted their dyspnea. Cluster analysis revealed that 12 groups of descriptors could be distinguished, each describing another experience of difficult breathing. Moreover, patients with different pathologies preferred certain clusters. "I feel wheezy" was typical for patients with asthma, while "I feel I need to sigh" was picked by patients with cardiac disease. On a second measurement, patients picked very similar sets of descriptors: The mean value of agreement was $77 \%$ (50\% expected if random; see also Mahler et al., 1996).

Simon et al. $(1989,1990)$ investigated which patterns of complaints were reported by a group of patients experiencing shortness of breath and by healthy participants. The patients had to indicate the sensations that were caused by their disease; the healthy participants rated their sensations when their breathing was affected in a number of ways (e.g., breath holding, breathing $\mathrm{CO}_{2}$, exercise, breathing with a fixed small volume). The authors selected 19 complaints that were frequently used by people reporting breathlessness and asked both groups to select the most prominent (salient) complaints. A factor analysis on the complaints indicated that patients with different diseases chose different clusters of complaints. The group of healthy participants made the distinction as well between the different ways their breath had been impeded and used approximately the same groups of complaints used by the patients to describe those sensations (Harver, Mahler, Schwartzstein, \& Baird, 2000; Simon et al., 1990; Table 1). This is in line with the conclusion of Simon et al. (1990) that each respiratory disorder probably causes a distinct sensation of breathlessness that is specific for the disease. Those clusters of complaints do not only map on particular diseases but also on sensations caused by different techniques to restrict breathing in healthy participants. Based on these findings, Simon et al. suggest that the clusters are based upon different (patho)physiological mechanisms that, each in its own way, give rise to feelings of dyspnea (see also Section 3).

Mahler and Harver (2000) refer to the research of Simon et al. (1989, 1990) to emphasize the importance of a thorough diagnostic process when a patient presents with dyspnea. Simon et al.'s clusters may be useful to differentiate between pathologies that cause dyspnea. The descriptors that are selected by patients may be helpful to the physician to make a correct diagnosis in addition to the standard physical examinations. For example, patients with asthma tend to select descriptors from the clusters exhalation, work, and tight, whereas patients with chronic obstructive pulmonary disease (COPD) frequently choose descriptors from the clusters effort and air hunger to characterize their experience of dyspnea (Simon et al., 1990). However, in a study with patients with lung cancer with different pathologies (tumor mass, metastases, pleural effusion, pleural thickening, etc.), the degree of overlap in the clusters between groups and the relatively low proportion of patients selecting the descriptors within each group suggested that the descriptors were insufficiently discriminating to be of use in differential diagnosis (Wilcock et al., 2002). This was the case despite the fact that for four of the six groups of patients, the clusters formed specific patterns of association suggesting that breathlessness varies qualitatively according to the underlying cause of breathlessness.

Skevington et al. (1997) point out that dyspnea is more than just a physical sensation: Important affective and evaluative components play a role. They asked a group of patients to describe in their own words how it felt to be short of breath and grouped those complaints into four categories. The first category consisted of physical sensations that could be clustered into groups comparable to those of Simon et al. (1989, 1990). The three other categories referred to affective consequences of dyspnea, lack of energy, and complaints of hyperventilation and speechlessness (items like "hoarseness," "cannot talk," and "lost speech"), respectively. Banzett, Dempsey, et al. (2000) emphasize the importance of the 
Table 1

Clusters of dyspneic sensations as reported by Simon et al. (1990) and some examples of conditions and particular stimuli they are associated with

\begin{tabular}{|c|c|c|c|c|c|c|c|c|}
\hline \multirow[t]{2}{*}{ Cluster } & \multirow[t]{2}{*}{ Descriptor } & \multicolumn{4}{|c|}{ Conditions } & \multicolumn{3}{|c|}{ Stimuli } \\
\hline & & Asthma & COPD & CHF & Preg & $\mathrm{CO}_{2}$ & BrHo & Exer \\
\hline 1. Rapid & I feel that my breathing is rapid. & & & $\mathrm{X}$ & & $\mathrm{X}$ & & $\mathrm{X}$ \\
\hline 2. Exhalation & My breath does not go out all the way. & $\mathrm{X}$ & & & & & & \\
\hline 3. Shallow & $\begin{array}{l}\text { My breath does not go in all the way. } \\
\text { My breathing is shallow. }\end{array}$ & & & & & & & \\
\hline 4. Work & $\begin{array}{l}\text { My breathing requires effort. } \\
\text { My breathing requires more work. }\end{array}$ & $\mathrm{X}$ & $\mathrm{X}$ & & & $\mathrm{X}$ & & \\
\hline 5. Suffocating & $\begin{array}{l}\text { I feel that I am smothering. } \\
\text { I feel that I am suffocating. }\end{array}$ & & & $\mathrm{X}$ & & & & \\
\hline 6. Hunger & $\begin{array}{l}\text { I feel a hunger for more air. } \\
\text { I feel out of breath. } \\
\text { I cannot get enough air. }\end{array}$ & & & $\mathrm{X}$ & $\mathrm{X}$ & & $\mathrm{X}$ & \\
\hline 7. Tight & $\begin{array}{l}\text { My chest feels tight. } \\
\text { My chest is constricted. }\end{array}$ & $\mathrm{X}$ & & & & & & \\
\hline 8. Heavy & $\begin{array}{l}\text { My breathing is heavy. } \\
\text { I feel that I am breathing more. }\end{array}$ & & & & & & & $\mathrm{X}$ \\
\hline
\end{tabular}

From the original 19-item list, 4 complaints ('I cannot take a deep breath,' 'I feel that my breath stops,' 'I am gasping for breath,' and 'My breathing requires more concentration') were deleted from analysis by Simon et al. (1990) because they did not cluster with other descriptors, because they were chosen infrequently, or because they did not discriminate between different sensations/pathologies.

$\mathrm{CHF}=$ congestive heart failure; $\mathrm{Preg}=$ pregnancy; $\mathrm{CO}_{2}=$ steady-state hypercapnia; $\mathrm{BrHo}=$ breath-holding; Exer = exercise 
affective dimension of dyspnea and relate it to the different aspects of the pain experience. Following these authors, the affective dimension in the dyspneic sensation leads to distress, which is the incentive for taking action. As mentioned in the introduction, dyspnea is also an important symptom in anxiety disorders, and panic and dyspnea are supposed to amplify one another (Moore \& Zebb, 1999). Moreover, brain research indicates that the perception of dyspnea and pain involves similar CNS structures (see below).

According to Skevington et al. (1997), the cluster of complaints related to lack of energy is important enough to be considered as independent from the more general physical discomfort: In their analyses, lack of energy was more closely related to emotion than to physical sensations.

In this first section, we argued that the term dyspnea is applicable to a wide range of phenomena which in turn are part of different pathologies. Although the patient's description may be a relevant indication of the underlying pathology and a first step towards a diagnosis, no diagnosis is complete without thorough physical examination.

The next section gives a brief and general overview of possible physiological mechanisms giving rise to dyspnea, without the intent to be comprehensive: Much more specialized publications than this article exist on the exact physiology of the lungs and lung mechanics (e.g., Barnes, Drazen, Rennard, \& Thomson, 2002) and on the (patho)physiology of dyspnea (for a review, see American Thoracic Society, 1999). As we mentioned in the introduction, our main focus will be on the psychological factors influencing (the perception of) dyspnea.

\section{Physiological mechanisms of dyspnea}

\subsection{Most prevalent explanations}

No specific dyspnea receptors exist and many different mechanisms may be involved (Manning \& Schwartzstein, 1995). Take the example of a person with bronchitis who gets short of breath after climbing the stairs to the office on the third floor. Is the shortness of breath the result of airway narrowing due to inflammation, is it caused by fatigue in respiratory muscles, or is it the result of changes in arterial blood gases? It might as well be a combination of two or more of those factors.

An early explanatory attempt stated that dyspnea was caused by a discrepancy between the effort of the respiratory muscles necessary to get air into the lungs and the actual amount of air that was displaced (inhaled). Respiratory muscle activity (mainly the muscles controlling the diaphragm and intercostal muscles) is controlled by the brainstem. The output generated in the brainstem was assumed to be compared to afferent information from mechanoreceptors in the diaphragm and intercostal muscles (Manning \& Schwartzstein, 1995): A lack of correspondence between the two results in a feeling of breathlessness (see also Rietveld, 1998, 2000). This is typically observed in dynamic hyperinflation, as seen in the case of increased respiratory resistance. Maintenance of ventilation requires higher muscular effort to overcome the increased resistance. This makes inspiration more effort-dependent, but at the same time requires expiration - usually a passive event due to elastic recoil of the lung and chest wallto be performed actively. As a consequence, expiration is often incomplete and air gets trapped inside the lungs, stretching the intercostal muscles. These are forced to operate outside their optimal range, resulting in intense muscle fatigue and dyspnea (Banzett, Dempsey, et al., 2000; Binks, Moosavi, Banzett, \& Schwarzstein, 2002). In patients with asthma, the overall increase in volume of the rib cage 
(i.e., hyperinflation) during a methacholine challenge is a better predictor of dyspnea than the actual reduction in lung function (Filippelli et al., 2003).

Breathing retraining is used in COPD to counteract dynamic hyperinflation. Pursed lip breathing improves gas exchange, decreases respiratory rate, increases tidal volume, and increases the activity of the inspiratory and expiratory muscles, thereby exerting a deflationary activity on the chest wall. Leaning forward decreases EMG activity of many respiratory muscles and increases efficiency of the diaphragm. Diaphragmatic breathing has also been suggested as a mean to reduce dyspnea, but it is possible that only patients with limited hyperinflation may benefit from it while severely hyperinflated patients are incapable of performing diaphragmatic breathing (Gigliotti, Romagnoli, \& Scano, 2003).

When respiratory muscle strength is reduced because of muscle weakness, a similar discrepancy between central motor command and muscle force can take place. A possible therapy consists of inspiratory muscle training. This technique is widespread in the treatment and rehabilitation of patients with COPD (American Thoracic Society, 1999; Weiner, Berar-Yanay, Davidovich, Magadle, \& Weiner, 2000; Weiner, Magadle, Massarwa, Beckerman, \& Berar-Yanay, 2002). Patients have to train their inspiratory muscles by breathing against an external load (at least 33\% of their maximal inspiratory effort for 30-60 min for 5-7 days a week, or by maximal inspiratory and expiratory effort every 3-5 min for periods of approximately $30 \mathrm{~min}$ daily, to be effective; Gigliotti, Romagnoli, et al., 2003). This increases muscle strength and endurance and helps to overcome increased airway resistance. In addition, the sensation of dyspnea decreases (Lötters, van Tol, Kwakkel, \& Gosselink, 2002).

Two different techniques are used, resistive loading and threshold loading. With resistive loading, a static resistance is applied, usually by limiting the diameter of the (inspiratory) tube of a breathing apparatus. This method, however, has the disadvantage that the pressure is flow dependent (i.e., a small tube can still be wide enough to take a relatively unimpeded slow breath). Threshold loading is independent of inspiratory flow rate, as it requires a buildup of negative pressure before flow occurs. An additional advantage of this method is that it enhances velocity of inspiratory muscle contraction, which is a favorable alteration of the breathing pattern as it shortens inspiratory time. This in turn increases time for expiration - and relaxation.

Another way to unload the inspiratory muscles is by supplying inspiratory pressure support.

Consistent with this explanation, Lougheed, Lam, Forkert, Web, and O'Donnell (1993) observed that inspiratory effort was the largest contributor to feelings of dyspnea in patients with asthma. The observed evolution of breathlessness and effort to breathe in was almost identical. In contrast, the curve for expiratory effort was situated just below the curve for inspiratory effort. This effect was, however, only apparent at a reduction of 50\% in lung function (forced expiratory volume in $1 \mathrm{~s}$ ), which is quite severe. Since dyspnea also occurs at less severe alterations in lung function, the impairment of muscle activity and higher breathing volume alone is not a sufficient explanation for dyspnea. Indeed, Binks et al. (2002) observed that mechanical ventilation reduced the intensity of perceived effort to breathe after methacholine-induced bronchoconstriction. The sensation of chest tightness or constriction, in contrast, remained unchanged during mechanical ventilation. Binks et al. conclude that the sensations of effort and tightness arise from different mechanisms.

Manning and Schwartzstein (1995) additionally mention the role of receptors in the lungs, airways, and chest. The lungs contain a number of different receptors that exchange information with the central nervous system. Stretch receptors, which react to inflation of the lung, are a first type and are of importance to end inspiration. Other types are nerve ends in alveolar walls and venae pulmonales that 
react to interstitial congestion in lung tissue and probably transfer information to the brain via the $N$. Vagus. The role of receptors in the airways is not clear, but there certainly is an influence of airflow on dyspnea. It is unknown whether the receptors in the airways are mechanoreceptors reacting to airflow as such or to changes in temperature that accompany airflow. The airway epithelium contains irritant receptors as well. Irritant receptors react to a variety of mechanical and chemical stimuli and play a role in bronchoconstriction. Finally, stretch receptors from the respiratory muscles send information to the central nervous system.

Another mechanism for dyspnea is a disturbance of blood gas levels. Initially, it was accepted that stimulation of chemoreceptors by heightened levels of arterial $\mathrm{CO}_{2}$ in itself was not sufficient to cause dyspnea and that muscle fatigue caused by increased ventilation - to eliminate $\mathrm{CO}_{2}$ from the body - was the main cause. However, research results showed that reduced ventilation (leading to decreased indices of effort, i.e., muscle activity on the one hand; but increased levels of $\mathrm{CO}_{2}$ in the blood on the other hand) caused significant increases in dyspnea (Schwartzstein, Simon, Weiss, Fencl, \& Weinberger, 1989). In addition, Banzett, Lansing, Reid, Adams, and Brown (1989) discovered that quadriplegic patients on mechanical ventilation reported dyspnea when their $\mathrm{CO}_{2}$ level was increased by lowering ventilation. Healthy people who were temporarily paralyzed by the injection of a neuromuscular blocker also reported severe shortness of breath when their $\mathrm{CO}_{2}$ level was augmented, a sensation they rated as very similar to a hypercapnic experience preceding paralysis (Banzett et al., 1990).

Evidence for this explanation comes from the effect of exercise training in COPD patients (Gigliotti, Coli, et al., 2003; Gigliotti, Romagnoli et al., 2003; Spruit, Troosters, Trappenurg, Decramer, \& Gosselink, 2004). Dyspnea and impaired exercise tolerance are everyday complaints of patients with COPD, and lung function impairment shows only a weak relation to impaired exercise tolerance. Other factors, such as peripheral muscle weakness, deconditioning, and impaired gas exchange in the lung and peripheral muscles are now recognized as important determinants. Positive effects of exercise training are, besides decreased reporting of dyspnea, improved aerobic metabolism and a delay in anaerobic threshold (Gigliotti, Coli, et al., 2003; Gigliotti, Romagnoli et al., 2003).

Lansing, Im, Thwing, Legedza, and Banzett (2000) link the sensation of respiratory work and effort to volume parameters of breathing via mechanoreceptors in respiratory muscles. According to these authors, the feeling of air hunger on the other hand is related to abnormal blood gas levels (via chemoreceptors), and they found that hypoxia causes feelings of air hunger comparable to the feeling of air hunger elicited by hypercapnia (Moosavi et al., 2003). The effects of hypoxia on respiration are not as clear as those of hypercapnia: The ventilatory response to hypoxia varies depending on the level of $\mathrm{CO}_{2}$ (Caruana-Montaldo, Gleeson, \& Zwillich, 2000) and it has been apparent that in conscious humans, the effect of progressive hypoxia on breathing is much greater if at the same time $\mathrm{CO}_{2}$ is rising than if it is steady or falling (Cunningham, Robbins, \& Wolff, 1986; Mohan \& Duffin, 1997).

\subsection{Other relevant findings}

Tetzlaff, Leplow, Ten Thoren, and Dahme (1999) reported that - at equal levels of reduction in lung function-inhalation of histamine led to more and more intense complaints than inhalation of methacholine. The difference in perceived intensity might be due to the localization of the bronchoconstriction. Methacholine presumably has the greatest effect on airways $2-4 \mathrm{~mm}$ in diameter (Desai \& Hansell, 2002). If airways of different width are affected by histamine versus methacholine, the resulting bronchoconstriction may lead to similar drops in lung function, but nevertheless elicit different 
sensations (Rietveld, 1998; Rietveld \& Prins, 1998). Turcotte, Corbeil, and Boulet (1990), on the other hand, found no differences between dyspnea elicited by different agents such as histamine, allergen, or exercise in patients with asthma, even though clearly different mechanisms were responsible for observed differences in lung function. Nevertheless, a different sensation of breathlessness can be expected when 'direct' bronchoconstrictive agents are used-e.g., methacholine - compared with agents that also have indirect effects, via C-fibers or vagal irritant receptors - e.g., histamine, bradykinin, or hypertonic saline (Grazzini et al., 2002).

Recently, brain imaging techniques have been used to identify brain structures that are involved in the perception of dyspnea (Banzett, Mulnier, et al., 2000; Evans et al., 2002; Mulnier et al., 1998). There are indications that the anterior insula, the cerebellar vermis, and the medial pons are activated during the perception of loaded breathing (Peiffer, Poline, Thivard, Aubier, \& Samson, 2001). The anterior insula has been detected in virtually all imaging studies of acutely induced pain, suggesting that the similarities between dyspnea and pain also apply to brain structures involved in their central processing. Activation in the anterior part of the insula has also been shown to be associated with the perception of various other predominantly unpleasant centrally processed sensations, such as aversive emotions, panic attacks, and also hunger and thirst (Peiffer et al., 2001).

The posterior cingulate gyrus, a part of the limbic area, may be involved in the integration of the effect of various factors that can change the perception of respiratory discomfort with little or no change in indices of respiratory motor response (Corfield et al., 1995; Peiffer et al., 2001). Peiffer et al. (2001) explicitly hypothesized that cognitive/emotional factors influence the perception of dyspnea since several regions in the posterior cingulate gyrus have been shown to be activated by predominantly unpleasant sensory-affective functions such as pain, thirst, hunger, emotion, and memory, as well as anxiety and its related symptoms (Liotti et al., 2001; Maddock, Buonocore, Kile, \& Garrett, 2003).

These findings are consistent with recent developments in the field of visceral sensations. According to Craig (2002) and Saper (2002), there is a forebrain sensory representation devoted to visceral sensation. Afferent input concerning bodily sensations of blood pressure, gastric stretch, taste, blood$\mathrm{CO}_{2}$ levels (air hunger), and pulmonary inflation (effort) reaches the brain via cranial (parasympathetic) nerves, whereas spinal (sympathetic) nerves carry information concerned with temperature as well as nociceptive visceral inputs related to mechanical, chemical, or thermal stimulation. This afferent neural system projects first to autonomic and homeostatic centers in the spinal cord and brainstem. Together with afferent activity that is relayed by the nucleus of the solitary tract (NTS), it generates a direct thalamocortical representation of the state of the body and represents all aspects of the physiological condition of all tissues of the physical body.

This "visceral sensory cortex" is posited in the insula, where a re-representation of the afferent information seems to constitute a primary interoceptive image of homeostatic afferents, a basis for the subjective evaluation of one's condition. Most probably, the organization of visceral sensations in the insular cortex is (organo)topographical, with some overlap between neurons responding to taste and gastrointestinal inputs or cardiovascular and respiratory inputs. The insular cortex relays information to medial temporal lobe structures, where it may be integrated with emotional experience; it is unlikely that the insular cortex itself functions as emotional integrator.

The information from the insular cortex is 'forwarded' to the orbitofrontal cortex. Both areas are activated during subjective emotions such as anger, disgust, or sexual arousal. The orbitofrontal cortex probably differentiates the affect associated with a bodily feeling, according to the body's homeostatic 
needs. In addition, the anterior cingulate cortex (ACC) is supposed to actively modulate the feelings represented by the image of the state of the body in the anterior insula.

Moreover, aside from the point of view that dyspnea is the result of feedback mechanisms reacting to alterations in physiological state, it might be interesting to consider a feed-forward mechanism in the etiology of dyspnea. We conceptualize the latter mechanism as a result of a discrepancy between the current breathing pattern - which can be perfectly in line with existing metabolic needs - and the breathing pattern that is associated with the expected metabolic needs and that would fit the action tendency underlying an emotional state (Frijda, 1999). For instance, dyspnea could be the result of a discrepancy between the current breathing pattern and the breathing pattern that would be associated with overt flight from a threat. As such, especially in anxiety states, dyspnea could be the result of a discrepancy between the current breathing pattern and the breathing pattern that is needed "in the face of the perceived danger."

Evidence for the influence of cognitive and emotional factors in the perception of dyspnea will be discussed in detail in subsequent sections of the article.

In summary, dyspnea is the consequence of a complex interaction of signals in the central nervous system and several receptors in the upper airways, lungs, and chest wall (see also Barnes et al., 2002; Fritz \& Wamboldt, 1998; Simon et al., 1989). The majority of conditions that cause dyspnea do so through a variety of mechanisms and physiological systems, and many disorders share the same mechanisms.

\section{The perception of dyspnea}

Rietveld (1998) adequately summarizes the previous paragraph by stating, "the sensory input into the symptom perception process is often neither clear nor specific" (p. 139). This is the very reason why research on dyspnea is hard to carry out: Although a certain correspondence exists between the physiological limitation of breathing (due to decreased lung volume, bronchus obstruction, or other causes) and the degree of dyspnea, the degree of correspondence varies strongly between and within persons. Back in 1976, Rubinfeld and Pain reported a remarkable discrepancy between the self-reported symptoms of their patients and the degree of pathophysiology present: For any given degree of airway obstruction, they observed a large variability in symptom intensity. This finding has been replicated repeatedly in the literature (see also Bijl-Hofland, Folgering, et al., 1999; Boulet, Leblanc, \& Turcotte, 1994; Burdon, Juniper, Killian, Hargreave, \& Campbell, 1982; Grazzini et al., 2002; Janson-Bjerklie, Ruma, Stulbarg, \& Carrieri, 1987; Kendrick, Higgs, Whitfield, \& Laszlo, 1993; Wamboldt, Bihun, Szefler, \& Hewitt, 2000).

Sensations, stimuli, and afferent information from lungs, chest wall, airways, throat, and other parts of the body have to be noticed and subsequently interpreted. The main part of the interpretation process is unconscious: Patients integrate the sensations at hand and label the whole as 'dyspnea.'

\subsection{Patient characteristics and perception of dyspnea}

Age, gender, airway reactivity, duration of the disease, fluctuations in the state of lungs and airways, degree of airway inflammation, speed of constriction, and localization of the reactivity have all been 
discussed as factors influencing the perception of dyspnea. Because the separate effects of the distinct factors are obscure and difficult to unravel, we discuss them together.

Tetzlaff et al. (1999) reported an effect of age: The older a person gets, the less accurate his or her perception (see also Cuttitta et al., 2001; Janson-Bjerklie et al., 1987). Higgs and Laszlo (1996) mentioned the age of 60 as the turning point. However, in many other studies, no effect of age could be observed (e.g., Bijl-Hofland, Cloosterman, Folgering, Akkermans, \& Van Schayck, 1999; Ottanelli et al., 2000). The potential effect of gender remains equally unclear. Some authors report that men are worse than women in the perception of dyspnea (Tetzlaff et al., 1999; Turner et al., 1998); others report the absence of any effect of gender (e.g., Bijl-Hofland, Cloosterman et al., 1999; Ottanelli et al., 2000). A study with children revealed that children younger than 10 years could use a Visual Analogue Scale (VAS) to indicate their asthma symptoms in line with lung function. In the group of children older than 10, no relationship was found between subjective and objective measures of asthma (Horak, Grässl, Skladal, \& Ulmer, 2003).

Boulet et al. (1994) found a normal distribution of the intensity of dyspnea experienced at a fall of $20 \%$ in forced expiratory volume in $1 \mathrm{~s}$ during histamine provocation tests. When they selected the patients whose rated intensity of dyspnea differed by more than one standard deviation from the mean (either above or below the mean: the so-called overperceivers and underperceivers, respectively), no differences in age, gender, or airway reactivity could be observed.

In patients with asthma, there is a negative relationship between bronchial reactivity and perceptual accuracy (see for instance Bijl-Hofland, Cloosterman et al., 1999; Koh, Choi, \& Lim, 2001; but for conflicting results, see van den Toorn, Overbeek, Prins, Hoogsteden, \& De Jongste, 2002). Patients with the most reactive airways - that is, the most severe cases - in general report less dyspnea than patients with less reactive airways. Bijl-Hofland, Folgering, et al. (1999) wondered what is cause and consequence: Does severe asthma lead to decreasing perceptual accuracy for dyspnea, or is the severity of the disease a consequence of the impaired perception because no remedial action is taken?

A possible explanation for the suboptimal perceptual accuracy in people with highly reactive airways is the existence of a perceptual mechanism that reacts to changes rather than to the state of the airways. Compared to people who commence a histamine provocation with 'open' airways, it has been found repeatedly that people with bronchoconstriction before the start of a histamine provocation show worse perceptual accuracy of histamine-induced constriction (see Burdon et al., 1982; Higgs \& Laszlo, 1996; Orehek, Beaupré, Badier, Nicoli, \& Delpierre, 1982; Ottanelli et al., 2000). Furthermore, Turcotte and Boulet (1993) reported that the time course of bronchoconstriction influences dyspnea symptoms. A rapid increase in airway resistance is probably adequately perceived, but once the constriction is installed its perception may fade. Additional constriction is then readily perceived, but without an accurate account of the existing obstruction.

In 't Veen et al. (1998) reported an influence of airway inflammation but did not comment on the direction of the causality. Inflammation may have a negative influence on the perception of dyspnea, but inflammation might as well be just an indication of airway instability (see also Roisman, Peiffer, Lacronique, Le Cae, \& Dusser, 1995). However, as is the case for age and gender, the effect of airway instability - considerable fluctuations in lung function values throughout the day, often treated as an equivalent of hyperreactivity - upon the perception of dyspnea remains unclear. Bijl-Hofland, Cloosterman, et al. (1999) and Bijl-Hofland, Folgering, et al. (1999) mentioned a reduced perceptual accuracy for dyspnea in patients with airway instability. On the other hand, Jones (1992) suggested that persons with a lot of variation in intensity of dyspnea will also be more accurate in judging its severity and intensity. 
Peiffer, Toumi, Razzouk, Marsac, and Lockhart (1992), in turn, reported the absence of a relationship between fluctuations in obstruction and perception of dyspnea. Moreover, the perception of bronchoconstriction of patients with asthma fluctuates during the day: Correlations between lung function and dyspnea (or estimates of lung function measurements) are in general smaller in the afternoon than early in the morning (Rietveld \& Prins, 1998). Rietveld and Prins (1998) further suggested that the location of (broncho)constriction - in central airways or in the periphery of the lungs - might be of great importance. Patients might sense both forms of constriction equally well, but the location of the constriction might influence lung function tests in a different manner. For instance, if peripheral obstruction is less reflected than central obstruction in lung function parameters, the problem of accuracy is no longer related to the patient's perception of dyspnea but instead to the measurement technique.

Jones (1992) took this one step further. According to him, there is a feedback mechanism in the perception of dyspnea. The output of the sensory system is fed back into the system, altering the perception process, which makes the state of the airways a bad predictor of dyspnea.

In addition, cultural differences may play an important role. Hardie, Janson, Gold, Carrieri-Kohlman, and Boushey (2000) asked a group of Afro-American and a group of Caucasian patients with asthma to describe their dyspnea during a methacholine provocation protocol (part of the diagnostic procedure for asthma). Their findings revealed differences not only in the descriptors participants from both groups selected, but also in the degree of dyspnea the groups reported. Afro-American patients with asthma reported less dyspnea and used mainly words and descriptors indicative of irritation of the throat and the upper airways ("tight throat," "voice tight," "itchy throat," "tough breath"), whereas Caucasian patients with asthma used lower airway descriptors suggesting chest wall discomfort ("deep breath," "aware of breathing," "hurts to breathe," "out of air"). Both groups nevertheless reported more discomfort related to airway obstruction when bronchoconstriction increased (as a result of methacholine inhalation).

In Chinese patients with cardiopulmonary diseases and medically unexplained dyspnea, spontaneously reported descriptors of breathlessness could be grouped into three factors: dyspnea-effort of breathing; dyspnea-affective aspect; and wheezing. Whereas the descriptors included in the factors effort and wheezing appeared to be similar to Western descriptors (Harver et al., 2000; Simon et al., 1989, 1990), the affective aspect bears some cultural specificity: Descriptors included in this factor are "blocked chi in the chest" and "blocked chi in the throat"; according to the concept of traditional Chinese medicine, chi is the living energy circulating along specific channels in the body. Moreover, the factors were related to specific disorders: Wheezing was linked to the diagnosis of asthma; the affective aspect of dyspnea was primarily linked to the diagnosis of medically unexplained dyspnea (Han et al., submitted for publication).

\section{Psychological influences on the perception of dyspnea}

From the previous paragraphs, one could get the impression that there is no clear link between a stimulus on the one hand and the sensation of dyspnea on the other hand. In fact, dyspnea in some cases is a true alarm of true suffocation and signals real dysfunctional processes in the body. Still, one must admit that the relation is problematic because of the variety of mechanisms involved. Moreover, it can be "heavily influenced by psychological processes" as well (Brand et al., 1992, p. 400). 


\subsection{Cue competition}

Older models of perception assume a limited capacity of (human) information processing (see Pennebaker, 1982, 2000; Rietveld \& Prins, 1998): Information from internal sensations must compete with external information to "catch" attention. The probability of noticing internal (bodily) information can be expressed as a function of the ratio of available internal and external information. When external information is salient, or attention is directed towards external cues, hardly any capacity will be available to process internal cues, and the probability that information about physical events reaches consciousness will be reduced.

A different conception of this idea of cue competition consists in the form of the "signal to noise" ratio, i.e., the amount of "dyspneic stimulus" in proportion to "nondyspneic stimulus" that is provided to the higher central nervous system centers. This was tested by Thornby, Haas, and Axen (1995) in patients with COPD: patients engaged in exercise while listening to music, grey noise, or silence. Exercise time was significantly longer, workload was significantly higher, and patients rated less exertion with music compared to grey noise or silence. Furthermore, use of headphones in the silent condition acted as a form of sensory deprivation and increased reports of exertion, simultaneously decreasing workload. According to the authors, auditory deprivation directed participants' attention to the discomforting physiologic and affective cues associated with respiratory effort and provided no competitive focus.

Similar results were observed in an attempt to preserve the beneficial effects of a pulmonary rehabilitation program: Patients with COPD who listened to music during two to five walking sessions a week reported less dyspnea while walking and even improved their functional performance further. This in contrast to patients who did not use music as a distractor: the latter could not maintain postpulmonary rehabilitation program gains (Bauldoff, Hoffman, Zullo, \& Sciurba, 2002). Ward, Macias, and Whipp (2001) suggested that even exercise per se could serve as an attention-diverting mechanism, thereby influencing the perception of dyspnea.

\subsection{Learning, previous experiences, and schemata}

One could assume that chronic patients become more accurate in time due to experience with their illness. However, the opposite is often true: The perception of chronic patients typically deteriorates with time (Rietveld \& Prins, 1998). According to Rietveld et al. (Rietveld \& Brosschot, 1999; Rietveld \& Prins, 1998), this is due to a process of selective perception, activated by cues in the environment or emotions associated with the aggravation of symptoms or disease state.

Indeed, after repeated exposure to the contingent presentation of situational or emotional cues together with symptoms, a mental representation of the association between the cues and the symptom is formed. Subsequently, the cues alone can give rise to selective symptom perception and aggravate blunted perception (De Peuter et al., submitted for publication; Devriese et al., 2000; Rietveld, Everaerd, \& van Beest, 1999; Van den Bergh, Stegen, \& Van de Woestijne, 1998; Van den Bergh, Winters, Devriese, \& Van Diest, 2002). Research with a respiratory learning paradigm revealed that healthy volunteers reported complaints based on an activated (unconscious) mental representation of learning experiences (Van den Bergh et al., 1998). These mental representations are similar to schemata: Based on experiences with episodes of a disease, patients will construct abstract mental representations including information about the cause, the time course, associated symptoms, possible 
cures, and treatments of a disease (Lacroix, Martin, Avendano, \& Goldstein, 1991; see also Horne \& Weinman, 2002).

In addition, the influence of cue competition as discussed above may be important in novice patients, but once the meaning of particular information has been established in memory, the impact of the competition of cues may diminish. Selective perception, response tendencies, and automatic triggers may become more important (Rietveld \& Brosschot, 1999).

\subsubsection{Learning}

Rietveld, Kolk, Prins, and Colland (1997) had children with asthma perform 5 min of walking in the hallway of a hospital. Subsequently, the children listened to a prerecorded tape with breathing sounds. They were told that they were listening to a recording of their own breathing. In fact, half of the group listened to a recording of wheezing, while the other half heard normal breathing sounds. Patients receiving the recording with wheezing reported significantly more dyspnea compared to the other group. According to the authors, children were uncertain about the state of their airways because they knew physical efforts may lead to asthma attacks. Hearing the wheezing sounds confirmed their schema ("exertion leads to asthma"). As a result, they were inclined to interpret other ambiguous physical sensations (like feeling faint or rapid breathing) as signs of asthma as well rather than as signs of fatigue (see also Barsky, Saintfort, Rogers, \& Borus, 2002). A similar effect was observed when children received false (negative) lung function information after exercise (Rietveld, Kolk, \& Prins, 1996).

Nouwen, Freeston, Cournoyer, Deschesnes, and Boulet (1994) investigated the effect of repeated methacholine provocations on the perception of dyspnea in patients with asthma and in a control group. The group with asthma performed better during the first methacholine-induced bronchoconstriction task, whereas during the second induction of bronchoconstriction approximately $1 \mathrm{~h}$ later, patients with asthma were less accurate. In contrast, the control group (participants without asthma) became more accurate in perceiving bronchoconstriction during the second test. This suggests that whereas patients at first detect asthma-related symptoms more accurately than controls, the nature of the task enabled them to rely on automated schemata, acquired through their earlier experience with similar symptoms. Control participants, who did not possess these cognitive schemata, learned during the testing periods to discriminate methacholine-related symptoms better.

\subsubsection{Previous experience}

Wilson and Jones (1990) carried out research about perception of dyspnea as a function of previous experiences with dyspnea. Their results suggest that the current perception of dyspnea is based upon a comparison with previous experiences. Patients as well as control participants hold a general representation of the (level of) dyspnea associated with certain efforts. The dyspnea experienced during or after an effort is compared to that "standard" and rated accordingly. Whenever a clearly divergent experience is encountered, the standard level is adapted to a new level and all subsequent dyspneic experiences are evaluated in comparison with the more recent one. It is not known for how long the effect can be observed: The study of Wilson and Jones used a time span of a few hours, whether the effect sustains after prolonged periods of time remains to be investigated. There is, however, some resemblance with the behavioral technique of desensitization, which increases accuracy of dyspnea perception (see further). 
Meek (2000) investigated the influence of attentional focus on perception of external resistive loads in patients with COPD. When instructed to rate the magnitude of six resistive loads and to simultaneously imagine they were "breathing as you typically do," patients perceived less difference between the loads compared to a condition without instruction. However, when they imagined "breathing as you did during your clearest memory of breathlessness," their perception significantly improved. Meek concluded that when the focus of attention is directed to previous experiences with, or exposure to, a sensation, then the intensity of a sensation is changed too-in line with the previous experience.

Rietveld et al. (1999) summarized as follows: "Ambiguous physical signals and contextual cues that mediate in biased symptom perception would be incorporated in recall schemata towards a firmly biased perceptual mechanism. Situational variables associated with initial attacks of breathlessness would develop into powerful triggers of this biased perceptual sequence" (p. 125).

\subsubsection{Schemata}

Bishop (1991) discussed the importance of prototypes in symptom perception. Participants were confronted with written sets of symptoms. These sets differed in the degree to which they were made up of "typical" sets of symptoms and the amount of "irrelevant" symptoms that were included. Upon recall, participants remembered more symptoms from high prototype sets than from low prototype or random sets. Furthermore, with low prototype sets, there was a slight tendency for participants to recall a larger proportion of symptoms consistent with their prototype for the disease in question. Participants remembered less well the irrelevant symptoms that had been presented. This effect was enhanced when participants were given an explicit diagnosis for the disease involved: Participants were even more likely to recall prototype-consistent symptoms and to neglect irrelevant ones. Bishop also suggested that patients who are expecting additional symptoms based on a disease prototype will be likely to actually feel those symptoms in addition to the symptoms already experienced.

Cameron, Leventhal, and Love (1998) argued that there is a reciprocal relationship between symptoms and disease schemata: Sensations activate related disease representations and these in turn cue a cognitive search for relevant symptoms. As a result, not only the detection of sensations will increase, but the attribution of sensations will also be more disease related. Cameron et al. also noted that this will especially be the case for vague or ambiguous symptoms and complaints.

Consistent with the influence of previous experiences on schemata and on the association of cues with (signs of) disease, the role of childhood experiences has been mentioned in the literature on symptom perception in panic patients. The way in which parents deal with physical complaints is a major determinant of the way children (learn to) deal with physical sensations (Barsky, 2000). Children assume that their parents' way of handling physical sensations is the right way. Children of parents who strongly attend to minor ailments, frequently visit a physician and extensively worry about small physical inconveniences probably will adopt this behavior and report great concern about physical sensations as adults. Parental attention can also be very rewarding for children, as is absence from school and special meals to comfort a sick child (Bouton, Mineka, \& Barlow, 2001; Ehlers, 1990, 1993; Fritz \& Wamboldt, 1998). As a result, symptoms will receive much attention and will be monitored (all too) carefully. 


\subsection{Personality and coping}

\subsubsection{Denial}

The main part of research on near-fatal asthma attacks has focused on personality. Yellowlees and Ruffin (1989) observed high levels of denial in the near-fatal group. Patients in their study reacted to their asthma with strong denial. When an attack occurred, they ignored the symptoms until the attack was so severe that medical intervention became necessary. After the attack, they reacted with increased denial or - if further denial was not possible - decompensation characterized by intense anxiety and/or panic. Campbell et al. (1995) concluded that denial indeed is a risk factor for near-fatal asthma attacks. Denial was related to complaints of "suddenly onsetting serious asthma" while low levels of denial were related to "slow deterioration." Patients who refuse to accept their condition are also characterized by limited compliance with therapeutic regimens (Adams, Pill, \& Jones, 1997).

Steiner, Higgs, Fritz, Laszlo, and Harvey (1987) suggested that this is not simply the consequence of denying specific symptoms, but of a broader, general repressive defense mechanism. Persons with this defense style are thought to notice signs of physical arousal but not to report them. Whether they truly deny their symptoms or, instead, are incapable of perceiving them cannot be determined. It is important to note that some people do perceive their symptoms very well but do not consult a physician because they do not attach high priority to the complaints (maybe even do not consider the sensations as "symptoms") and consider other things (work, family, short-term engagements) as more important (Abraham, Costa-Pereira, Du, Florey, \& Ogston, 1999).

\subsubsection{Negative affectivity}

Janson, Björnsson, Hetta, and Boman (1994) documented a correlation between depression and anxiety and reporting of asthma symptoms. On the other hand, there appeared to be no correlation between anxiety and depression and objective measurements of asthma severity. In a recent study, clinical dyspnea scores in patients with asthma were found to be determined by three independent factors: age, airway obstruction, and emotional status (Martinez-Moragón, Perpiñá, Belloch, de Diego, \& Martínez-Francés, 2003), and patients with asthma with comorbid panic disorder reported significantly higher levels of perceived breathlessness during induced bronchoconstriction, although their mean fall in lung function was very comparable to that of asthmatic patients without panic disorder (Van PeskiOosterbaan, Spinhoven, Van der Does, Willems, \& Sterk, 1996). Similarly to the distinction we made between denial and inability to perceive symptoms, we must ask whether anxious and depressed patients are better in perceiving their bodily sensations or rather tend to report more complaints. Cameron et al. (1998) concluded a brief overview of the literature as follows, “... anxiety-related traits are not associated with poorer health or increased susceptibility to disease; instead, they are associated with biases in somatic perception and tendencies to overreport symptoms" (p. 459).

Research within our group consistently found that persons with a high level of negative affectivity (NA; a general tendency to experience negative emotions, but also characteristics such as introversion, negative self-image, and dwelling on failures and shortcomings) report more symptoms than persons low in NA (Put, 2001; Put, Demedts, Van den Bergh, Demyttenaere, \& Verleden, 1999; Stegen et al., 1998; Stegen, Van Diest, Van de Woestijne, \& Van den Bergh, 1999; Van Diest et al., 2003). We also found that patients admitted to hospital with medically unexplained dyspnea reported more intense dyspnea and anxiety than patients with an established organic cause for their dyspnea. In addition, in daily life and after voluntary hyperventilation, the "nonorganic" patients reported more frequent and intense 
complaints from diverging categories (dizziness, blurred vision, headache, tingling sensations, shaking hands, anxiety, palpitations, etc.). A striking characteristic of patients with nonorganic dyspnea was that they were more anxious and reported more dyspnea than patients with medically explained dyspnea (Han et al., in press).

Smith and Nicholson (2001) found that persons high in trait NA reported more complaints when they suffered from an upper respiratory tract infection compared to people low in trait NA, independently from disease severity. According to Larsen (1992), such biases might be due to the retrospective nature of the majority of symptom questionnaires. In Larsen's study, high NA persons tended to recall physical symptoms as being worse than they really were.

Van Diest et al. (submitted for publication) suggest yet another factor possibly contributing to the NA-symptom relationship: some overlap between words or phrases that people use to report both psychological and physiological stress. For example, whereas "tooth ache" refers quite clearly to a physical condition, phrases like "fatigue" or "suffocating feeling" - both part of the sensation of dyspnea - may refer to both psychological and physical conditions. It might be that for high NA people, the difference between the physiological process of dyspnea and the psychological process of anxiety is not clear.

\subsection{A dynamic perspective on perceptual accuracy}

The variables we just discussed are all considered rather stable across situations and over time. High NA people are supposed to report more complaints and to do so consistently, deniers are supposed to cope with their disease state by ignoring symptoms, patients in general are supposed to have disease representations that provide them with an overall schema of a (proto)typical disease episode.

On the other hand, there seems to be an influence of anxiety. Nouwen et al. (1994) suggested that the patients in their methacholine provocation study (see Section 5.2) were able to switch to the more economical processing in terms of schemata only because anxiety was low. In a suggestion study, however, Put et al. (in press) observed a significant correlation between anxiety ratings and symptoms of airway obstruction, to the extent that they concluded that participants inferred their asthma state based on anxiety cues. In addition, a recent study showed a strong impact of context upon interoceptive accuracy (Van den Bergh et al., 2004): High NA participants were less accurate in their perception of changes in breathing pattern, but this was only the case when they were experiencing the induced sensations within a threatening information frame.

We would suggest to leave the question "What kind of person reports too little (or too much) complaints" and switch to the following one, "What information in what kind of context is used by what kind of person to experience and express what kind of symptom?" in order to promote the study of interoceptive accuracy as a result of a dynamic perceptual process in an active information processing individual. This should allow us to specify in the long run under which circumstances interoception will be accurate or inaccurate and why.

\section{Is there anything we can do?}

It should be clear from the former paragraphs that all too often, no simple cure or remedy is available for dyspnea. If the underlying cause is clear, appropriate treatment is possible (e.g., anti-inflammatory 
agents, additional oxygen, surgery, etc.), but in many cases this does not alleviate dyspnea completely. Nebulized fentanyl citrate has been suggested as an inexpensive mean to alleviate dyspnea in cancer patients (Coyne et al., 2002), and nebulized morphine or other opioids have been reported to have a beneficial effect, although the mechanism is not clear (Zebraski, Kochenash, \& Raffa, 2000).

In this final section, we can only suggest possible ways to deal with it. First, at the stage of diagnosis, objective as well as subjective measures have to be taken into account. Questionnaires, general complaint scales, and specific complaints reported by the patient are all valuable tools. Objective measures are needed to evaluate the severity of physiological pathology; subjective measures (e.g., which descriptors the patient uses to describe dyspnea) can provide hints to the physician about the underlying pathology. Additionally, comparing subjective reports with data from physical investigations can provide a way to identify "bad" perceivers (patients who overreport symptoms as well as patients who hardly perceive any airway change) and may provide insight in the impact of the disease on the patient's life and the way the patient perceives, frames, and handles the 'problem.' In trying to optimize the subjective well-being of the patient, the latter are valuable clues. This is discussed under Section 8.1 (see infra).

Asthmatic patients with psychiatric comorbidity may confuse the symptoms from their psychiatric disturbance with asthma and report more dysfunction than is justified by their pathology (Campbell et al., 1995; Rietveld \& Creer, 2003). Katon, Sullivan, and Walker (2001) add that some respiratory symptoms are in fact DSM-IV symptoms but sometimes are not recognized as such by the physician. Therefore, it is important to prevent misinterpretation both from the patient's and the physician's side (Section 8.2, see infra).

Finally, we emphasize the importance of (recognizing) denial: Deniers make believe that nothing is wrong (Section 8.3, see infra).

\subsection{Inaccurate perception}

Considering the widespread discrepancy between subjective feelings of dyspnea and underlying pathology, patients who are not capable to estimate their physical state must be identified as soon as possible. Patients with asthma can be identified during a histamine (or methacholine) provocation test if they simultaneously fill out a measure of subjective discomfort or dyspnea. Especially those patients who do not perceive significant changes in the state of their respiratory system are at a higher risk for a (near-)fatal attack.

It is important that such underperceivers learn to assess their lung function accurately as soon as possible. One possibility to increase the perceptual accuracy for changes in airway functioning is training with a peak-flow meter. Poor perceivers who estimate peak flow twice daily and subsequently measure peak flow, improved after 10 measurements (Silverman et al., 1987; see also Harver \& Katkin, 1998). Patients receiving feedback about the accuracy of their estimations also became more accurate in detection of increases in the flow-resistive component of breathing (Harver, 1994).

\subsection{Misinterpretation of symptoms}

It is possible that seemingly poor perceivers do notice changes in the state of their airways but do not interpret these sensations as such. For them it is sufficient to learn to associate the feeling of airway 
changes with fluctuations in peak flow. Moreover, according to Nouwen et al. (1994), many patients are fairly able to distinguish between the uncomfortable feeling associated with shortness of breath and sensations due to physiological changes. In addition, patients are able to distinguish between different sensations of dyspnea arising from different physiological systems (e.g., ratings of work and effort vs. air hunger; American Thoracic Society, 1999; Harver et al., 2000; Lansing et al., 2000). Yet, a lot of patients base their remedial actions on the subjective feeling of discomfort. In this case, extensive information about the importance of correct medication use and some training in identifying the specific signs of airway changes can provide a solution.

Dyspnea is a common symptom in panic attacks (Carr, 1998), and anxiety/panic probably contributes considerably to the overreporting of symptoms (Put, 2001). In a study by Dorhofer and Sigmon (2002), women with asthma and at least one panic attack in the past year reported more symptoms of psychological distress and more negative perceptions of bodily functioning than women with only asthma and control participants. Conversely, respiratory sensations in patients with both respiratory disease and panic disorder form a source of opportunities to misinterpret these sensations in a catastrophical manner and increase panic symptomatology (Moore \& Zebb, 1999).

There is no clear-cut solution to this problem. Still, in many cases, extensive information about the disease, medication regimen, and contacts with fellow patients considerably reduces worrying. The precise mechanism is unclear, but as a result patients report fewer complaints. If anxiety persists, a thorough examination - and treatment - of the cause of anxiety is necessary. Therapeutical techniques are widespread; safe and effective pharmacotherapy requires attention to adverse drug effects though: Most anxiolytics tend to depress ventilatory function. Nonpharmacological treatments such as cognitive behavioral therapies offer effective treatment without the risk of medication side effects (Smoller et al., 1999). We mention relaxation therapy and cognitive restructuring as two possibilities. Dorhofer and Sigmon (2002) suggest teaching patients with asthma to minimize catastrophic interpretations of general bodily sensations and the use of cognitive strategies to reduce negative beliefs about the consequences of experiencing asthma symptoms. In addition, it may be useful to teach individuals with both asthma and panic attacks to distinguish between asthma sensitivity and anxiety sensitivity.

As we already mentioned in Section 5.1, music is an effective attention-diverting strategy, reducing dyspnea during exercise. An additional advantage is that exercise can be performed at a higher intensity and for a longer duration, potentially leading to more effective reconditioning training. Bauldoff et al. (2002) suggested music with a tempo of approximately $90-100 \mathrm{bpm}$, with the style of music adapted to the personal preferences of the patient - e.g., classical music, country, pop, folk, etc.

Apart from the distractive effect, music can be used to help people relax. Patients receiving ventilatory assistance reported significantly less state anxiety after a single music-aided relaxation session of $30 \mathrm{~min}$ compared to a group with only relaxation (Wong et al., 2001). Additionally, heart rate and respiratory rate decreased (Chlan, 1998), as well as blood pressure (Wong et al., 2001). Similar effects were observed with patients undergoing colonoscopy: Heart rate, systolic and diastolic blood pressure, and state anxiety decreased among a music intervention group during the intervention while remaining unchanged in a control group. Moreover, less sedation was required in the music group (Smolen, Topp, \& Singer, 2002). Psychologists and social workers can play an important role in implementing these techniques to reduce anxiety, worry, and panic.

As we pointed out earlier, aerobic training also has a positive effect on dyspnea. Hallstrand, Bates, and Schoene (2000) reported a decrease in dyspnea, better lung function at rest, and less exercise-induced 
bronchospasm in children as a result of aerobic training. The results in adults comprise less suffering from exercise-induced asthma, increased quality of life, and increased exercise tolerance. We suggest that part of this effect is due to a decrease in asthma-related anxiety and concerns. Aerobic training can be considered as a kind of exposure therapy_or desensitization-for patients with asthma. This effect might even be increased by a positive effect of aerobic exercise on anxiety sensitivity and fear of anxiety-related bodily sensations as well (Broman-Fulks, Berman, Rabian, \& Webster, 2004).

This effect was also observed in a group of healthy participants: When tested over a period of 10 days to 10 weeks, their dyspnea ratings for a given level of ventilation decreased. The 'slope' of the relationship remained the same, but the overall level of dyspnea was lower towards the last testing occasion (Subhan, Butler, \& Reed, 2003). There was a concurrent effect of decreasing heart rate, so a possible role of physical fitness cannot be ruled out. However, because the decline in breathlessness scores stopped after approximately 5-6 sessions and heart rate continued to decline until the last session, the authors suggest that part of the effect must be attributed to "psychological factors" (i.e., desensitization).

But once again, a moderate degree of disease-specific panic/fear can be adaptive: It keeps one alert and is a good incentive to take action when symptoms emerge (Carr, 1998; Greaves, Eiser, Seamark, \& Halpin, 2002). Brand et al. (1992) mentioned the fact that patients with asthma are slightly better in perceiving changes in airway pathology than COPD patients. This is an adaptive strategy for both groups: Patients with asthma need quick reactions, whereas COPD patients with a good perception would only be confronted with their steadily deteriorating disease over and over again.

According to Gigliotti, Romagnoli, et al. (2003), improvement in clinical symptoms (i.e., dyspnea) after breathing retraining is a more consistent finding than any measurable impact on physiological parameters. Spruit et al. (2004) add that fear of shortness of breath often results in avoidance of physical activity in patients with COPD. This enhances not only exercise intolerance, but also social isolation. Rehabilitation programs including exercise training may increase ambulation and, in that way, reduce the social deprivation and isolation.

\subsection{Denial}

Patients ignoring symptoms or denying disease should be assisted in the process of acceptance of symptoms and disorder (Adams et al., 1997). In our view, behavioral techniques like cognitive restructuring and relaxation can be of great help. In an initial contact, with full contribution of the patient, specific areas of concern or anxieties can be identified. Thereafter, these can be targeted with the aforementioned techniques. One must, however, exert caution and avoid psychological decompensation (Yellowlees \& Ruffin, 1989).

\section{General conclusion}

Dyspnea is a complaint in many disorders and refers to a variety of subjective experiences. Depending on the physiological processes that play a role in the etiology, dyspnea may present in different forms. Although no precise mechanism has been identified, there is consensus that a variety of receptors in lung tissue, airways, upper respiratory tract, and thorax, as well as chemoreceptors in lungs and blood vessels together with multiple brain areas, add to the feeling of dyspnea. 
Moreover, patient characteristics_-physical as well as psychological-influence the perception of dyspnea. Previous experiences with illness episodes, stored in memory in illness schemata, bias current perception. In the same way can the perception of dyspnea be disturbed by emotions (especially negative emotions), whether they are directly related to the condition that causes dyspnea or not.

Therefore, whenever a patient presents with dyspnea, it is important to perform a thorough examination, including objective as well as subjective measures.

\section{Acknowledgements}

The first author was supported by Grant G.0270.01-FWO Flanders and BIL 01/05 of the Bilateral Scientific and Technological Cooperation between Flanders (Belgium) and China. The authors would like to express their gratitude to Dr. K. P. Van de Woestijne for valuable comments on previous versions of this paper.

\section{References}

Abraham, C., Costa-Pereira, A., Du, V., Florey, C., \& Ogston, S. (1999). Cognitions associated with initial medical consultations concerning recurrent breathing difficulties: A community-based study. Psychology and Health, 14, 913-925.

Adams, S., Pill, R., \& Jones, A. (1997). Medication, chronic illness and identity: The perspective of people with asthma. Social Science \& Medicine, 45, 189-201.

American Psychiatric Association (1994). Diagnostic and statistical manual of mental disorders (4th ed.). Washington, DC: Author.

American Thoracic Society (1999). Dyspnea. Mechanisms, assessment, and management: A consensus statement. American Journal of Respiratory and Critical Care Medicine, 159, 321-340.

Banzett, R. B., Dempsey, J. A., O’Donnell, D. E., \& Wamboldt, M. Z. (2000). Symptom perception and respiratory sensation in asthma. American Journal of Respiratory and Critical Care Medicine, 162, 1178-1182.

Banzett, R. B., Lansing, R. W., Brown, R., Topulos, G. P., Yager, D., Steele, S. M., Londono, B., Loring, S. H., Reid, M. B., Adams, L., \& Nations, C. S. (1990). 'Air hunger' from increased $\mathrm{PCO}_{2}$ persists after complete neuromuscular block in humans. Respiration Physiology, 81, 1-17.

Banzett, R. B., Lansing, R. W., Reid, M. B., Adams, L., \& Brown, R. (1989). 'Air hunger' arising from increased PCO $_{2}$ in mechanically ventilated quadriplegics. Respiration Physiology, 76, 53-67.

Banzett, R. B., Mulnier, H. E., Murphy, K., Rosen, S. D., Wise, R. J., \& Adams, L. (2000). Breathlessness in humans activates insular cortex. NeuroReport, 11, 2117-2120.

Barnes, P., Drazen, J., Rennard, S., \& Thomson, N. (2002). Asthma and COPD. Basic mechanism and clinical management. London: Academic Press.

Barsky, A. J. (2000). The validity of bodily symptoms in medical outpatients. In A. A. Stone, J. S. Turkkan, C. A. Bachrach, J. B. Jobe, H. S. Kurtzman, \& V. S. Cain (Eds.), The science of self-report. Implications for research and practice (pp. 339-361). London: Lawrence Erlbaum Associates.

Barsky, A. J., Saintfort, R., Rogers, M. P., \& Borus, J. F. (2002). Nonspecific medication side effects and the nocebo phenomenon. Journal of the American Medical Association, 287, 622-627.

Bauldoff, G. S., Hoffman, L. A., Zullo, T. G., \& Sciurba, F. C. (2002). Exercise maintenance following pulmonary rehabilitation. Effects of distractive stimuli. Chest, 122, 948-54.

Bijl-Hofland, I. D., Cloosterman, S. G. M., Folgering, H. Th. M., Akkermans, R. P., \& van Schayck, C. P. (1999). Relation of the perception of airway obstruction to the severity of asthma. Thorax, 54, 15-19.

Bijl-Hofland, I. D., Folgering, H. Th. M., van den Hoogen, H., Cloosterman, S. G. M., Van Weel, C., Donkers, J. M., \& Van Schayck, C. P. (1999). Perception of bronchoconstriction in asthma patients measured during histamine challenge test. European Respiratory Journal, 14, 1049-1054. 
Binks, A. P., Moosavi, S. H., Banzett, R. B., \& Schwarzstein, R. M. (2002). "Tightness" sensation of asthma does not arise from the work of breathing. American Journal of Respiratory and Critical Care Medicine, 165, 78-82.

Bishop, G. D. (1991). Understanding the understanding of illness: Lay disease representations. In J. A. Skelton, \& R. T. Croyle (Eds.), Mental representations in health and illness (pp. 32-59). New York: Springer.

Black, D. W., Okiishi, C., \& Schlosser, S. (2001). The Iowa follow-up of chemically sensitive persons. Annals of the New York Academy of Sciences, 933, 48-56.

Boulet, L. -P., Leblanc, P., \& Turcotte, H. (1994). Perception scoring of induced bronchoconstriction as an index of awareness of asthma symptoms. Chest, 105, 1430-1433.

Bouton, M. E., Mineka, S., \& Barlow, D. H. (2001). A modern learning theory perspective on the etiology of panic disorder. Psychological Review, 108, 4-32.

Brand, P. L. P., Rijcken, B., Schouten, J. P., Koëter, G. H., Weiss, S. T., \& Postma, D. S. (1992). Perception of airway obstruction in a random population sample. Relationship to airway hyperresponsiveness in the absence of respiratory symptoms. American Review of Respiratory Disease, 146, 396-401.

Broman-Fulks, J. J., Berman, M. E., Rabian, B. A., \& Webster, M. J. (2004). Effects of aerobic exercise on anxiety sensitivity. Behaviour Research and Therapy, 42, 125-136.

Burdon, J. G. W., Juniper, E. F., Killian, K. J., Hargreave, F. E., \& Campbell, E. J. M. (1982). The perception of breathlessness in asthma. American Review of Respiratory Disease, 126, 825-828.

Cameron, L. D., Leventhal, H., \& Love, R. R. (1998). Trait anxiety, symptom perceptions, and illness-related responses among women with breast cancer in remission during a tamoxifen clinical trial. Health Psychology, 17, 459-469.

Campbell, D. A., Yellowlees, P. M., McLennan, G., Coates, J. R., Frith, P. A., Gluyas, P. A., Latimer, K. M., Luke, C. G., Martin, A. J., \& Ruffin, R. E. (1995). Psychiatric and medical features of near fatal asthma. Thorax, 50, $254-259$.

Carr, R. E. (1998). Panic disorder and asthma: Causes, effects and research implications. Journal of Psychosomatic Research, 44, 43-52.

Caruana-Montaldo, B., Gleeson, K., \& Zwillich, C. W. (2000). The control of breathing in clinical practice. Chest, 117, $205-225$.

Chlan, L. (1998). Effectiveness of a music therapy intervention on relaxation and anxiety for patients receiving ventilatory assistance. Heart and Lung, 27, 169-176.

Corfield, D. R., Fink, G. R., Ramsay, S. C., Murphy, K., Harty, H. R., Watson, J. D. G., Adams, L., Frackowiak, R. S., \& Guz, A. (1995). Evidence for limbic system activation during $\mathrm{CO}_{2}$-stimulated breathing in man. Journal of Physiology, 488, 77-84.

Coyne, P. J., Viswanathan, R., \& Smith, T. J. (2002). Nebulized fentanyl citrate improves patients' perceptions of breathing, respiratory rate, and oxygen saturation in dyspnea. Journal of Pain and Symptom Management, 23, $157-160$.

Craig, A. D. (2002). How do you feel? Interoception, the sense of the physiological condition of the body. Nature Reviews. Neuroscience, 3, 655-666.

Cunningham, D. J. C., Robbins, P. A., \& Wolff, C. B. (1986). Integration of respiratory responses to changes in alveolar partial pressures of $\mathrm{CO}_{2}$ and $\mathrm{O}_{2}$ and in arterial $\mathrm{pH}$. In A. P. Alfred (Ed.), Handbook of physiology. Section 3: The respiratory System II. Control of breathing (pp. 475-520). Bethesda: American Physiological Society.

Cuttitta, G., Cibella, F., Bellia, V., Grassi, V., Cossi, S., Bucchieri, S., \& Bonsignore, G. (2001). Changes in FVC during methacholine-induced bronchoconstriction in elderly patients with asthma. Bronchial hyperresponsiveness and aging. Chest, 119, 1685-1690.

De Peuter, S., Van Diest, I., Lemaigre, V., Wan, L., Verleden, G., Demedts, M., \& Van den Bergh, O. (2004). Can asthma symptoms be learned? (Manuscript submitted for publication).

Desai, S. R., \& Hansell, D. M. (2002). Imaging. In P. Barnes, J. Drazen, S. Rennard, \& N. Thomson (Eds.), Asthma and COPD. Basic mechanisms and clinical management (pp. 465-480). London: Academic Press.

Devriese, S., Winters, W., Stegen, K., Van Diest, I., Veulemans, H., Nemery, B., Eelen, P., Van de Woestijne, K. P., \& Van den Bergh, O. (2000). Generalization of acquired somatic symptoms in response to odors: A Pavlovian perspective on multiple chemical sensitivity. Psychosomatic Medicine, 62, 751-759.

Dorhofer, D. M., \& Sigmon, S. T. (2002). Physiological and psychological reactivity in women with asthma: The effects of anxiety and menstrual cycle phase. Behaviour Research and Therapy, 40, 3-17.

Ehlers, A. (1990). Somatic symptoms in panic attacks: Interoception, fear of fear, and learning experiences. In H. G. Zapotoczky, \& T. Wenzel (Eds.), The scientific dialogue: From basic research to clinical intervention (pp. 127-132). Amsterdam: Swets and Zeitlinger. 
Ehlers, A. (1993). Somatic symptoms and panic attacks: A retrospective study of learning experiences. Behaviour Research and Therapy, 31, 269-278.

Elliott, M. W., Adams, L., Cockcroft, A., Macrae, K. D., Murphy, K., \& Guz, A. (1991). The language of breathlessness. Use of verbal descriptors by patients with cardiopulmonary disease. American Review of Respiratory Disease, 144, $826-832$.

Evans, K. C., Banzett, R. B., Adams, L., McKay, L., Frackowiak, R. S. J., \& Corfield, D. R. (2002). BOLD fMRI identifies limbic, paralimbic, and cerebellar activation during air hunger. Journal of Neurophysiology, 88, 1500-1511.

Filippelli, M., Duranti, R., Gigliotti, F., Bianchi, R., Grazzini, M., Stendardi, L., \& Scano, G. (2003). Overall contribution of chest wall hyperinflation to breathlessness in asthma. Chest, 124, 2164-2170.

Frijda, N. H. (1999). De Emoties (The Emotions). Amsterdam: Uitgeverij Bert Bakker.

Fritz, G. K., \& Wamboldt, M. Z. (1998). Pediatric asthma. Psychosomatic interactions and symptom perception. In H. Kotses, \& D. A. Harver (Eds.), Self-management of asthma (pp. 195-230). New York: Marcel Dekker.

Gigliotti, F., Coli, C., Bianchi, R., Romagnoli, I., Lanini, B., Binazzi, B., \& Scano, G. (2003). Exercise training improves exertional dyspnea in patients with COPD. Evidence of the role of mechanical factors. Chest, 123, 1749-1802.

Gigliotti, F., Romagnoli, I., \& Scano, G. (2003). Breathing retraining and exercise conditioning in patients with chronic obstructive pulmonary disease (COPD): A physiological approach. Respiratory Medicine, 97, 197-204.

Grazinni, M., Ottanelli, R., Duranti, R., Stenardi, L., Ronchi, M. C., Romagnoli, I., \& Scano, G. (2002). Measures of perception of bronchoconstriction and clinical and functional data are not interrelated in asthma. Respiration, 69, 496-501.

Greaves, C. J., Eiser, C., Seamark, D., \& Halpin, D. M. G. (2002). Attack context: An important mediator of the relationship between psychological status and asthma outcomes. Thorax, 57, 217-221.

Hallstrand, T. S., Bates, P. W., \& Schoene, R. B. (2000). Aerobic conditioning in mild asthma decreases the hyperpnea of exercise and improves exercise and ventilatory capacity. Chest, 118, 1460-1469.

Han, J., Zhu, Y., Li, Sh., Luo, D., Chen, X., Hu, Z., Put, C., Van de Woestijne, K. P., \& Van den Bergh, O. (2004). Respiratory complaints in Chinese: Cultural and diagnostic specificities (submitted for publication).

Han, J. N., Zhu, Y. J., Li, Sh. W., Luo, D. M., Hu, Z., Van Diest, I, De Peuter, S., Van de Woestijne, K. P., \& Van den Bergh, O. (2004). Medically unexplained dyspnea: Psychophysiological characteristics and role of breathing therapy. Chinese Medical Journal, 117, 6-13.

Hardie, G. E., Janson, S., Gold, W. M., Carrieri-Kohlman, V., \& Boushey, H. A. (2000). Word descriptors used by AfricanAmerican and white asthma patients during induced bronchoconstriction. Chest, 117, 935-943.

Harver, A. (1994). Effects of feedback on the ability of asthmatic subjects to detect increases in the flow-resistive component to breathing. Health Psychology, 13, 52-62.

Harver, A., \& Katkin, E. S. (1998). Modification of respiratory perceptions. In H. Kotses, \& A. Harver (Eds.), Self-management of asthma (pp. 407-433). New York: Marcel Dekker.

Harver, A., Mahler, D. A., Schwartzstein, R. M., \& Baird, J. C. (2000). Descriptors of breathlessness in healthy individuals. Distinct and separable constructs. Chest, 118, 679-690.

Higgs, C. M. B., \& Laszlo, G. (1996). Perception of asthma. In L. Adams, \& A. Guz (Eds.), Lung biology in health and disease. Respiratory sensation (pp. 285-309). New York: Marcel Dekker.

Horak, E., Grässl, G., Skladal, D., \& Ulmer, H. (2003). Lung function and symptom perception in children with asthma and their parents. Pediatric Pulmonology, 35, 23-28.

Horne, R., \& Weinman, J. (2002). Self-regulation and self-management in asthma: Exploring the role of illness perceptions and treatment beliefs in explaining non-adherence to preventer medication. Psychology and Health, 17, 17-32.

In 't Veen, J. C. C., Smits, H. H., Ravensberg, A. J. J., Hiemstra, P. S., Sterk, P. J., \& Bel, E. H. (1998). Impaired perception of dyspnea in patients with severe asthma: Relation to sputum eosinophils. American Journal of Respiratory and Critical Care Medicine, 158, 1134-1141.

Janson-Bjerklie, S., Ruma, S. S., Stulbarg, M., \& Kohlman Carrieri, V. (1987). Predictors of dyspnea intensity in asthma. Nursing Research, 36, 179-183.

Janson, C., Björnsson, E., Hetta, J., \& Boman, G. (1994). Anxiety and depression in relation to respiratory symptoms in asthma. American Journal of Respiratory and Critical Care Medicine, 149, 930-934.

Jones, P. W. (1992). Breathlessness perception in airways obstruction. European Respiratory Journal, 5, 1035-1036.

Katon, W., Sullivan, M., \& Walker, E. (2001). Medical symptoms without identified pathology: Relationship to psychiatric disorders, childhood and adult trauma, and personality traits. Annals of Internal Medicine, 134, 917-925. 
Kendrick, A. H., Higgs, C. M. B., Whitfield, M. J., \& Laszlo, G. (1993). Accuracy of perception of severity of asthma: Patients treated in general practice. BMJ, 307(6901), 422-424.

Koh, Y. I., Choi, I. S., \& Lim, H. (2001). Airway responsiveness as a direct factor contributing to the dyspnoea perception in asthma. Respiratory Medicine, 95, 464-470.

Lacroix, M. J., Martin, B., Avendano, M., \& Goldstein, R. (1991). Symptom schemata in chronic respiratory patients. Health Psychology, 10, 268-273.

Lansing, R. W., Im, B. S. H., Thwing, J. I., Legedza, A. T. R., \& Banzett, R. B. (2000). The perception of respiratory work and effort can be independent of the perception of air hunger. American Journal of Respiratory and Critical Care Medicine, 162 , $1690-1696$.

Larsen, R. J. (1992). Neuroticism and selective encoding and recall of symptoms: Evidence from a combined concurrentretrospective study. Journal of Personality and Social Psychology, 62, 480-488.

Liotti, M., Brannan, S., Egan, G., Shade, R., Madden, L., Abplanalp, B., Robillard, R., Lancaster, J., Zamarripa, F. E., Fox, P. T., \& Denton, D. (2001). Brain responses associated with consciousness of breathlessness (air hunger). Proceedings of the National Academy of Sciences, 98, 2035-2040.

Lötters, F., van Tol, B., Kwakkel, G., \& Gosselink, R. (2002). Effects of controlled inspiratory muscle training in patients with COPD: A meta-anlysis. European Respiratory Journal, 20, 570-576.

Lougheed, M. D., Lam, M., Forkert, L., Webb, K. A., \& O’Donnell, D. E. (1993). Breathlessness during acute bronchoconstriction in asthma. American Review of Respiratory Disease, 148, $1452-1459$.

Maddock, R. J., Buonocore, M. H., Kile, S. J., \& Garrett, A. S. (2003). Brain regions showing increased activation by threatrelated words in panic disorder. NeuroReport, 14, 325-328.

Mahler, D. A., \& Harver, A. (2000). Do you speak the language of dyspnea? Chest, 117, 928-929.

Mahler, D. A., Harver, A., Lentine, T., Scott, J. A., Beck, K., \& Schwartzstein, R. M. (1996). Descriptors of breathlessness in cardiorespiratory diseases. American Journal of Respiratory and Critical Care Medicine, 154, 1357-1363.

Manning, H. L., \& Schwartzstein, R. M. (1995). Pathophysiology of dyspnea. New England Journal of Medicine, 333, $1547-1553$.

Martinez-Moragón, E., Perpiñá, M., Belloch, A., de Diego, A., \& Martínez-Francés, M. (2003). Determinants of dyspnea in patients with different grades of stable asthma. Journal of Asthma, 40, 375-382.

Meek, P. (2000). Influence of attention and judgment on perception of breathlessness in healthy individuals and patients with chronic obstructive pulmonary disease. Nursing Research, 49, 11-9.

Mohan, R., \& Duffin, J. (1997). The effect of hypoxia on the ventilatory response to carbon dioxide in man. Respiration Physiology, 108, 101-115.

Moore, M. C., \& Zebb, B. J. (1999). The catastrophic misinterpretation of physiological distress. Behaviour Research and Therapy, 37, 1105-1108.

Moosavi, S. H., Golestanian, E., Binks, A. P., Lansing, R. W., Brown, R., \& Banzett, R. B. (2003). Hypoxic and hypercapnic drives to breathe generate equivalent levels of air hunger in humans. Journal of Applied Physiology, 94, $141-154$.

Mulnier, H. E., Adams, L., Murphy, K., Rosen, S. D., Wise, R. J. S., \& Banzett, R. B. (1998). Areas of cerebral cortex activated by dyspnoea. NeuroImage, 7, 5430 .

Noseda, A., Schmerber, J., Prigogine, T., de Maertelaer, V., \& Yernault, J. -C. (1995). Perception of dyspnea during acute changes in lung function in patients with either asthma or COPD. Respiratory Medicine, 89, 477-485.

Nouwen, A., Freeston, M. H., Cournoyer, I., Deschesnes, F., \& Boulet, L. -P. (1994). Perceived symptoms and discomfort during induced bronchospasm: The role of temporal adaptation and anxiety. Behaviour Research and Therapy, 32, $623-628$.

Orehek, J., Beaupré, A., Badier, M., Nicoli, M. M., \& Delpierre, S. (1982). Perception of airway tone by asthmatic patients. Bulletin Europeen de Physiopathologie Respiratoire, 18, 601-607.

Ottanelli, R., Rosi, E., Romagnoli, I., Ronchi, M. C., Lanini, B., Grazzini, M., Filippelli, N., Stenardi, L., Duranti, R., \& Scano, G. (2000). Perception of bronchoconstriction and bronchial hyper-responsiveness in asthma. Clinical Science, 98, $681-687$.

Peiffer, C., Poline, J. B., Thivard, L., Aubier, M., \& Samson, Y. (2001). Neural substrates for the perception of acutely induced dyspnea. American Journal of Respiratory and Critical Care Medicine, 163, 951-957.

Peiffer, C., Toumi, M., Razzouk, H., Marsac, J., \& Lockhart, A. (1992). Relationship between spontaneous dyspnea and lability of airway obstruction in asthma. Clinical Science, 82, 717-724.

Pennebaker, J. W. (1982). The psychology of physical symptoms. New York: Springer-Verlag.

Pennebaker, J. W. (2000). Psychological factors influencing the reporting of physical symptoms. In A. A. Stone, J. S. Turkkan, 
C. A. Bachrach, J. B. Jobe, H. S. Kurtzman, \& V. S. Cain (Eds.), The science of self-report. Implications for research and practice (pp. 299-315). London: Lawrence Erlbaum Associates.

Put, C. (2001). Symptom perception in asthma. Medicine meets psychology. Unpublished doctoral dissertation, University of Leuven, Belgium.

Put, C., Demedts, M., Van den Bergh, O., Demyttenaere, K., \& Verleden, G. (1999). Context-evoked asthma complaints without pulmonary changes in patients with high negative affectivity. American Journal of Respiratory and Critical Care Medicine, 159, 240.

Put, C., Van den Bergh, O., Van Ongeval, E., De Peuter, S., Demedts, M., \& Verleden, G. (in press). Negative affectivity and the influence of suggestion on asthma symptoms. Journal of Psychosomatic Research.

Rietveld, S. (1998). Symptom perception in asthma: A multidisciplinary review. Journal of Asthma, 35, 137-146.

Rietveld, S. (2000). Paradoxical breathlessness in asthma. Behaviour Research and Therapy, 38, 1193-1203.

Rietveld, S., \& Brosschot, J. F. (1999). Current perspectives on symptom perception in asthma: A biomedical and psychological review. International Journal of Behavioral Medicine, 6, 120-134.

Rietveld, S., \& Creer, T. L. (2003). Psychiatric factors in asthma. Implications for diagnosis and therapy. American Journal of Respiratory Medicine, 2, 1-10.

Rietveld, S., Everaerd, W., \& van Beest, I. (1999). Can biased symptom perception explain false-alarm choking sensations? Psychological Medicine, 29, 121-126.

Rietveld, S., Kolk, A. M., \& Prins, P. J. M. (1996). The influence of lung function information on self-reports of dyspnea by children with asthma. Journal of Pediatric Psychology, 21, 367-377.

Rietveld, S., Kolk, A. M., Prins, P. J. M., \& Colland, V. T. (1997). The influence of respiratory sounds on breathlessness in children with asthma: A symptom-perception approach. Health Psychology, 16, 547-553.

Rietveld, S., Everaerd, W., \& Creer, T. L. (2000). Stress-induced asthma: a review of research and potential mechanisms. Clinical and Experimental Allergy, 30, 1058-1066.

Rietveld, S., \& Prins, P. J. M. (1998). Children's perception of physical symptoms. The example of asthma. Advances in Clinical Child Psychology, 20, 153-182.

Roisman, G. L., Peiffer, C., Lacronique, J. G., Le Cae, A., \& Dusser, D. J. (1995). Perception of bronchial obstruction in asthmatic patients. Relationship with bronchial eosinophilic inflammation and epithelial damage and effect of corticosteriod treatment. Journal of Clinical Investigation, 96, 12-21.

Rubinfeld, A. F., \& Pain, M. C. F. (1976). Perception of asthma. Lancet, 1, 882.

Saper, C. B. (2002). The central autonomic nervous system: Conscious visceral perception and autonomic pattern generation. Annual Review of Neuroscience, 25, 433-469.

Schwartzstein, R. M., Simon, P. M., Weiss, J. W., Fencl, V., \& Weinberger, S. E. (1989). Breathlessness induced by dissociation between ventilation and chemical drive. American Review of Respiratory Disease, 139, 1231-1237.

Silverman, B. A., Mayer, D., Sabinsky, R., Williams-Akita, A., Feldman, J., Schneider, A. T., \& Chiaramonte, L. T. (1987). Training perception of airflow obstruction in asthmatics. Annals of Allergy, 59(5), 350-344.

Simon, P. M., Schwartzstein, R. M., Weiss, J. W., Fencl, V., Teghtsoonian, M., \& Weinberger, S. E. (1990). Distinguishable types of dyspnea in patients with shortness of breath. American Review of Respiratory Disease, 142, 1009-1014.

Simon, P. M., Schwartzstein, R. M., Weiss, W. J., Lahive, K., Fencl, V., Teghtsoonian, M., \& Weinberger, S. E. (1989). Distinguishable sensations of breathlessness induced in normal volunteers. American Review of Respiratory Disease, 140, $1021-1027$.

Skevington, S. M., Pilaar, M., Routh, D., \& MacLeod, R. D. (1997). On the language of breathlessness. Psychology and Health, 12, 677-689.

Smith, A., \& Nicholson, K. (2001). Psychosocial factors, respiratory viruses and exacerbations of asthma. Psychoneuroendocrinology, 26, 411-420.

Smolen, D., Topp, R., \& Singer, L. (2002). The effect of self-selected music during colonoscopy on anxiety, heart rate, and blood pressure. Applied Nursing Research, 16, 126-136.

Smoller, J. W., Simon, N. M., Pollack, M. H., Kradin, R., \& Stern, T. (1999). Anxiety in patients with pulmonary disease: Comorbidity and treatment. Seminars in Clinical Neuropsychiatry, 4, 84-97.

Spruit, M. A., Troosters, T., Trappenburg, J. C. A., Decramer, M., \& Gosselink, R. (2004). Exercise training during rehabilitation of patients with COPD: A current perspective. Patient Education and Counseling, 52, 243-248.

Stegen, K., Neujens, A., Crombez, G., Hermans, D., Van de Woestijne, K. P., \& Van den Bergh, O. (1998). Negative affect, respiratory reactivity, and somatic complaints in a $\mathrm{CO} 2$ enriched air inhalation paradigm. Biological Psychology, 49, 109-122. 
Stegen, K., Van Diest, I., Van de Woestijne, K. P., \& Van den Bergh, O. (1999). Negative affectivity and bodily sensations induced by $5,5 \% \mathrm{CO}_{2}$ enriched air inhalation: The role of interpretative processes. Psychology and Health, 15, 1-15.

Steiner, H., Higgs, C. M. B., Fritz, G. K., Laszlo, G., \& Harvey, J. E. (1987). Defense style and the perception of asthma. Psychosomatic Medicine, 49, 35-44.

Subhan, M. M. F., Butler, T. J., \& Reed, J. W. (2003). Effect of repetitive exercise testing on breathlessness in humans. Clinical Science, 105, 243-250.

Tetzlaff, K., Leplow, B., ten Thoren, C., \& Dahme, B. (1999). Perception of dyspnea during histamine- and metacholineinduced bronchoconstristion. Respiration, 66, 427-433.

Thornby, M. A., Haas, F., \& Axen, K. (1995). Effect of distractive auditory stimuli on exercise tolerance in patients with COPD. Chest, 107, 1213-1217.

Turcotte, H., \& Boulet, L. -P. (1993). Perception of breathlessness during early and late asthmatic responses. American Review of Respiratory Disease, 148, 514-518.

Turcotte, H., Corbeil, F., \& Boulet, L. -P. (1990). Perception of breathlessness during bronchoconstriction induced by antigen, exercise, and histamine challenges. Thorax, 45, 914-918.

Turner, M. O., Noertjojo, K., Vedal, S., Bai, T., Crump, S., \& Fitzgerald, J. M. (1998). Risk factors for near-fatal asthma. American Journal of Respiratory and Critical Care Medicine, 157, 1804-1809.

Van den Bergh, O., Stegen, K., \& Van de Woestijne, K. P. (1998). Memory effects on symptom reporting in a respiratory learning paradigm. Health Psychology, 17, 241-248.

Van den Bergh, O., Winters, W., Devriese, S., \& Van Diest, I. (2002). Learning subjective health complaints. Scandinavian Journal of Psychology, 43, 147-152.

Van den Bergh, O., Winters, W., Devriese, S., Van Diest, I., Vos, G., \& De Peuter, S. (2004). Accuracy of respiratory symptom perception in persons with high and low negative affectivity. Psychology and Health, 19, 213-222.

van den Toorn, L. M., Overbeek, S. E., Prins, J. -B., Hoogsteden, H. C., \& De Jongste, J. C. (2002). Dyspnoea perception during clinical remission of atopic asthma. European Respiratory Journal, 19, 1047-1050.

Van Diest, I., De Peuter, S., Eertmans, A., Notebaert, K., Victoir, A., \& Van den Bergh, O. (2004). Negative affectivity and subjective health: A closer look into the relationship (Manuscript submitted for publication).

Van Diest, I., Vuerstaek, S., Corne, I., De Peuter, S., Devriese, S., Van de Woestijne, K. P., \& Van den Bergh, O. (2003). Resting end-tidal $\mathrm{CO}_{2}$ and negative affectivity. Psychosomatic Medicine, 65, 976-983.

Van Peski-Oosterbaan, A. S., Spinhoven, P., Van der Does, A. J. W., Willems, L. N. A., \& Sterk, P. J. (1996). Is there a specific relationship between asthma and panic disorder? Behaviour Research and Therapy, 34, 333-340.

Wamboldt, M. Z., Bihun, J. T., Szefler, S., \& Hewitt, J. (2000). Perception of induced bronchoconstriction in a community sample of adolescents. Journal of Allergy and Clinical Immunology, 106, 1102-1017.

Ward, S. A., Macias, D., \& Whipp, B. J. (2001). Is breath-hold time an objective index of exertional dyspnea in humans? European Journal of Applied Physiology, 85, 272-279.

Weiner, P., Berar-Yanay, N., Davidovich, A., Magadle, R., \& Weiner, M. (2000). Specific inspiratory muscle training in patients with mild asthma with high consumption of inhaled B2-agonists. Chest, 117, 722-727.

Weiner, P., Magadle, R., Massarwa, F., Beckerman, M., \& Berar-Yanay, N. (2002). Influence of gender and inspiratory muscle training on the perception of dyspnea in patients with asthma. Chest, 122, 197-201.

Wilcock, A., Crosby, V., Hughes, A., Fielding, K., Corcoran, R., \& Tattersfield, A. E. (2002). Descriptors in breathlessness in patients with cancer and other cardiorespiratory diseases. Journal of Pain and Symptom Management, 23, $182-189$.

Wilson, R. C., \& Jones, P. W. (1990). Influence of prior ventilatory experience on the estimation of breathlessness during exercise. Clinical Science, 78, 149-153.

Wong, H. L. C., Lopez-Nahas, V., \& Molassiotis, A. (2001). Effects of music therapy on anxiety in ventilator-dependent patients. Heart and Lung, 30, 376-387.

Yellowlees, P. M., \& Ruffin, R. E. (1989). Psychological defenses and coping styles in patients following a life-threatening attack of asthma. Chest, 95, 1298-1303.

Zebraski, S. E., Kochenash, S. M., \& Raffa, R. B. (2000). Lung opioid receptors: pharmacology and possible target for nebulized morphine in dyspnea. Life Sciences, 66, 2221-2231. 